\title{
A Review on Biomedical Waste and its Management
}

\author{
Sharma $\mathrm{P}^{1 *}$, Sharma $\mathrm{A}^{2}$, Jasuja $\mathrm{ND}^{3}$ and Somani $\mathrm{PS}^{4}$ \\ ${ }^{1}$ Department of Zoology, Stani Memorial PG College, India \\ ${ }^{2}$ Department of Biotechnology, Stani Memorial PG College, India \\ ${ }^{3}$ Department of Agriculture, Vivekananda Global University, India \\ ${ }^{4}$ Department of Zoology, Mahatma Jyoti Rao Phoole University, India
}

*Corresponding author: Preeti Sharma, Department of Zoology, Stani Memorial PG College, Jaipur-302020, Rajasthan, India

Submission: March 03, 2018; Published: June 06, 2018

\begin{abstract}
Biomedical waste is highly hazardous which can give rise to serious diseases that may be fatal; therefore it is a matter of global concern. Biomedical waste management is of great importance to reduce the serious health implications. This article deals with the basic issues of biomedical waste disposal and management of biomedical waste. Its purpose is to spread knowledge among the personnel involved in health care services to prevent transmission of the diseases in the society and to protect public health and environment.
\end{abstract}

Keywords: Biomedical waste; Diseases; Health care services; Public health; Environment

\section{Introduction}

Biomedical waste is any kind of waste either solid or liquid containing harmful materials generated by healthcare facilities e.g. hospitals, practices, health camps etc. This waste consists of human tissues, contaminated blood, body fluids, discarded medicines, drugs, contaminated cotton, dressings, and sharps such as needles, glass, blades, scalpels, lancets [1]. Biomedical waste collection and disposal has greatest risk to healthcare, sanitation workers and the general community.The biomedical waste without proper sterilization leads to acquired immune deficiency syndrome (AIDS), Hepatitis B \& C, severe acute respiratory syndrome (SARS), tetanus, psychosocial trauma etc. [2]. Biomedical waste management is important to protect the environment and health of the population.

\section{Necessity of Biomedical Waste Management}

Improper management of waste generated in health care facilities causes a direct health hazards on the society, the health care workers and on the environment. There is a requirement for the management of biomedical waste to minimize the risk of infection outside the hospital for waste handlers, scavengers and those living in the vicinity of hospitals. Management is also needed due to the risk of air, water, and soil pollution, or due to improper incineration emissions and ash. It plays an important role in disposal of the discarded drugs that can be repacked and sold off [3].

\section{Biomedical Waste Management}

Biomedical waste management is of great significance because biomedical waste can adversely affect health inviting serious implications to the people who get in touch with it. Segregation, storage and safe disposal of the waste is the key to the effective managementof biomedical waste in a workplace $[4,5]$.

\section{Segregation of Biomedical Waste}

Segregation of waste plays a major role for improved biomedical waste management. It is important to reduce the volume of infectious waste otherwise the quantum of waste will go beyond the control of management [6]. The waste is segregated according to different color coding system of waste containers which is given below:

A. Red bag: Recyclable contaminated waste such as bottles, intravenous tubes, catheters, urine bags, syringes and gloves.

B. Yellow bag: Human and animal anatomical waste, soiled waste including items contaminated with blood, body fluids like dressings, plaster casts, cotton swabs, expired or discarded medicines, chemical waste (liquid), discarded linen, mattresses, beddings contaminated with blood or body fluid, microbiology, biotechnology and other clinical laboratory waste.

C. Black bag: Incineration ash and chemical waste (solid).

D. White bag: Waste sharps including needles, scalpels, blades, or any other contaminated sharp object that may cause puncture and cuts.

E. Blue bag: Metallic body implants and glassware such as medicine vials, ampoules. 


\section{Storage of Biomedical Waste}

Healthcare facilities must provide a storage area for medical waste until it is collected for treatment and disposal. Storage area should be selected carefully which is unapproachable to the general public and must exhibit warning symbols \& signs. It should be stored in a dry andsecured area beforebeing transported.The area must be protected from water, wind, rodents, insects and animals. Hazardous biomedical waste should not be stored for more than 3 months [7].

\section{Treatment of Biomedical Waste}

Biomedical waste treatment refers to the processes to eradicate the deleterious effects of the waste. There are several treatment optionswhich maximize safety during handling and disposal of the waste. It also minimizes environmental hazards. Incineration, Autoclaving, irradiation and chemical treatments are the most common methods used for treatment and decontamination of biomedical waste.

\section{Incineration}

It is a treatment process used to convert pathological and pharmaceutical waste into ash, flue gases and heat.Operating temperature for incineration should be in the range of $800-1400 \mathrm{oC}$. It decreases the mass of waste by $90-95 \%$ and thus reducesadverse effects on the environment [8].

\section{Autoclaving}

It is a process of steam sterilization and is the most common alternative to incineration. Autoclaving requires a temperature of $121 \mathrm{oC}$ and pressure of about 15 pounds per square inch (psi) for 20-30 minutes.This treatment is applied to inactivate the infectious agents and to sterilize the equipment used in medical services. It is less costly and carries no documented health impacts [9].

\section{Chemical treatment}

This treatment is often used to decontaminate liquid waste, so that it can be disposed off locally. It makes use of several techniques such as oxidation, reduction, precipitation and $\mathrm{pH}$ neutralization to convert waste into less hazardous substances. Chlorine, sodium hydroxide or calcium oxide can be usedaccording to the nature of waste [10].

\section{Irradiation}

These systems are presently being used in waste treatment operations which include gamma, electron-beam, ultraviolet and $\mathrm{X}$-rays. Irradiation sterilizes waste in an enclosed chamber by exposing it to a radioactive cobalt- 60 which gives out gamma rays that are lethal to micro-organisms.It is very expensive as compared to other methods and precautions must be taken to protect workers from harmful effects of radiations such as cancer, radiation sickness or even death [11].

\section{Disposal of Biomedical Waste}

Land disposal is typically used for remediation of waste which is decontaminated by above applicable treatment methods. This method is generally used in developing countries which involves the dumping of waste into a landfill. Land-filling should be done at locations where groundwater level is low and which are far from flooding sources. Radioactive wastes are generally dumped in the oceans far away from human habitations. Every state and local government has its own rules and regulations for disposal of disinfected waste [12]

\section{Advantages of BMW Management}

Planning the waste management and recycling for all of the waste generated in the health care facilities is a crucial task which plays an exceptionally important role in the worldwide cleanliness, public health, conservation of resources and sustainability of the ecosystem. Recycling medical waste minimizes utilization of raw material and reduces the amount of the waste materials that must be disposed in a landfill. It reduces the hazards and risks to the community which can be acquired by hospital. Reduction in the occurrence of HIV/AIDS, sepsis, hepatitis, and other diseases transmitted by infectious medical equipments takes place by proper waste management [13]. Illegal trading of used syringes, injection needles and medical tools can also be prevented by proper management strategies. Awareness about hazards of biomedical waste and its proper disposal is required for a safe and healthy future $[14,15]$.

\section{Conclusion}

Waste generation should be minimized for the protection of environment and general public health.People must be sensitized to the issues related to biomedical waste and should participate in the programs organized for waste minimization. The medical employees must be trained to create awareness and foster responsibilities for prevention of exposure and unsafe disposal to the waste. Medical personnel should strictly follow all the rules and regulations implemented by concerned governing bodies.

\section{References}

1. Yadavannavar MC, Berad AS, Jagirdar PB (2010) Biomedical waste management: A study of knowledge, attitude, and practices in a tertiary health care institution in Bijapur. Indian J Community Med 35(1): 170171

2. Bhagawati G, Nandwani S, Singhal S (2015) Awareness and practices regarding bio-medical waste management among health care workers in a tertiary care hospital in Delhi. Indian J Med Microbiol 33(4): 580-582.

3. Aggarwal H, Kumar P (2015) Need for biomedical waste management. J Med Soc 29(1): 58-59.

4. Shrestha D, Gokhe SB, Dhoundiyal A, Bothe P (2017) A case study to review compliance to biomedical waste management rules in a tertiary care hospital. Int J Community Med Public Health 4(2): 511-515.

5. Capoor MR, Bhowmik KT (2017) Current perspectives on biomedical waste management: Rules, conventions and treatment technologies. Indian J Med Microbiol 35(2): 157-164.

6. Mishra K, Sharma A, Sarita, Ayub S (2016) A study: Biomedical waste management in India. IOSR-JESTFT 10(5): 64-67.

7. Sarsour A, Ayoub A, Lubbad I, Omran A, Shahrour I (2014) Assessment of medical waste management within selected hospitals in Gaza strip Palestine: A pilot study. Int J Sci Res Environ Sci 2(5): 164-173. 
8. Ferdowsi A, Ferdosi M, Mehrani MJ (2013) Incineration or autoclave? A comparative study in Isfahan hospitals waste management system. Mat Soc Med 25(1): 48-51.

9. Chudasama RK, Rangoonwala M, Sheth A, Misra SKC, Kadri AM, et al. (2013) Biomedical waste management: A study of knowledge, attitude and practice among healthcare Personnel at tertiary care hospital in Rajkot. J Res Med Den Sci 1(1): 17-22.

10. Hirani DP, Villaitramani KR, Kumbhar SJ (2014) Biomedical waste: An introduction to its management. IJIRAE 1(8): 82-87.

11. Zimmermann K (2017) Microwave as an emerging technology for the treatment of biohazardous waste: A mini-review. Waste Manag Res 35(5): 471-479.
12. Ghasemi MK, Yusuff RB (2016) Advantages and disadvantages of healthcare waste treatment and disposal alternatives: Malaysian scenario. Pol J Environ Stud 25(1): 17-25.

13. Murakami H, Kobayashi M, Zhu X (2003) Risk of transmission of hepatitis B virus through childhood immunization in northwest China. Soc Sci Med 57(10): 1821-1832.

14. Arora M (2013) Hospital waste: Management \& handling. IJOART 2(11): 238-245.

15. David JJ, Shanbag P (2016) Awareness and practices regarding biomedical waste management among health-care workers in a tertiary care hospital in Delhi: Comment. Indian J Med Microbiol 34(3): 391-392. (c) (i) Creative Commons Attribution 4.0

For possible submissions Click Here

\section{Submit Article}

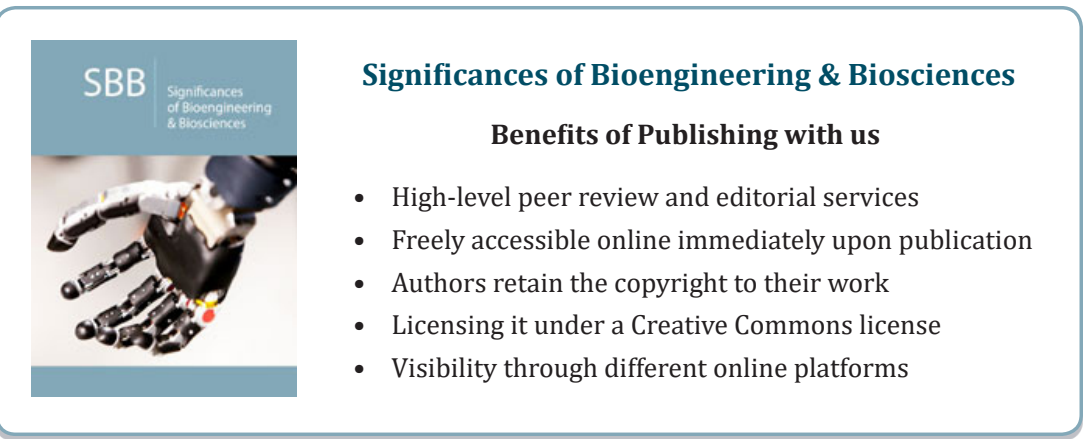

